\title{
X-Ray absorption spectroscopy investigation of 1-alkyl-3-methylimidazolium bromide salts
}

\author{
Paola D'Angelo, ${ }^{1, a)}$ Andrea Zitolo, ${ }^{1}$ Valentina Migliorati, ${ }^{1}$ Enrico Bodo, ${ }^{1}$ Giuliana Aquilanti, ${ }^{2}$ \\ Jean Louis Hazemann, ${ }^{3}$ Denis Testemale, ${ }^{3}$ Giordano Mancini, ${ }^{4}$ and Ruggero Caminiti ${ }^{1}$ \\ ${ }^{1}$ Dipartimento di Chimica, Università di Roma "La Sapienza", P. le A. Moro 5, 00185 Roma, Italy \\ ${ }^{2}$ Sincrotrone Trieste S.C.p.A s.s. 14, km 163.5, I-34149 Basovizza, Trieste, Italy \\ ${ }^{3}$ Institut Neel, Département MCMF, 25 Avenue des Martyrs, 38042 Grenoble and FAME beamline at ESRF, \\ 38043 Grenoble, France \\ ${ }^{4}$ CASPUR, Inter-University Consortium for Supercomputing in Research, via dei Tizii 6b, 00185 Roma, Italy
}

(Received 21 June 2011; accepted 27 July 2011; published online 18 August 2011)

\begin{abstract}
X-ray absorption spectroscopy (XAS) has been used to unveil the bromide ion local coordination structure in 1-alkyl-3-methylimidazolium bromide $\left[\mathrm{C}_{n} \mathrm{mim}\right] \mathrm{Br}$ ionic liquids (ILs) with different alkyl chains. The XAS spectrum of 1-ethyl-3-methylimidazolium bromide has been found to be different from those of the other members of the series, from the butyl to the decyl derivatives, that have all identical XAS spectra. This result indicates that starting from 1-buthyl-3-methylimidazolium bromide the local molecular arrangement around the bromide anion is the same independently from the length of the alkyl chain, and that the imidazolium head groups in the liquid ILs with long alkyl chains assume locally the same orientation as in the $\left[\mathrm{C}_{4} \mathrm{mim}\right] \mathrm{Br}$ crystal. With this study we show that the XAS technique is an effective direct tool for unveiling the local structural arrangements around selected atoms in ILs. @ 2011 American Institute of Physics. [doi:10.1063/1.3625920]
\end{abstract}

\section{INTRODUCTION}

Ionic liquids (ILs) are an emerging class of solvents that are fluid at room temperature, and consist entirely of ionic species. They are typically built up by organic cations and inorganic anions, have negligible vapor pressure and thus are nonvolatile, and they are nonflammable under ambient conditions. These properties have led to the application of ILs as solvents for synthesis and catalysis, and as alternative media for extractions and purifications. ${ }^{1-4}$ The exploitation of the technologically appealing properties of ILs requires a detailed understanding of their structural and dynamical features at atomic level. ${ }^{5}$ In particular, the characterization of the molecular organization and dynamics of ILs as a function of cation and anion nature, ${ }^{6-8}$ concentration in the case of mixture with other compounds, ${ }^{9-11}$ and temperature ${ }^{12,13}$ is very important to understand the relations between their molecular and macroscopic properties.

Among the various IL families, 1-alkyl-3methylimidazolium $\left[\mathrm{C}_{n} \mathrm{mim}\right]$ salts are the most widely used and a deep understanding of their structural properties, such as the nature of the interaction between the imidazolium cation and the anion, and the role of the hydrogen bonds is extremely important. Combined $\mathrm{x}$-ray and neutron-diffraction experiments of crystalline and liquid $\left[\mathrm{C}_{4} \mathrm{mim}\right]\left[\mathrm{PF}_{6}\right]$ (Ref. 14) and $\left[\mathrm{C}_{1} \mathrm{mim}\right] \mathrm{Cl}$ (Ref. 15) were interpreted using the crystal geometry as a model to derive the structure of the liquid. The existence of local structures in the liquid reminiscent of those in the crystalline phase was proposed from the analysis of Raman and x-ray diffraction data taken on $\left[\mathrm{C}_{4} \mathrm{mim}\right] \mathrm{Cl}$, $\left[\mathrm{C}_{4} \mathrm{mim}\right] \mathrm{Br}$, and $\left[\mathrm{C}_{4} \mathrm{mim}\right] \mathrm{I} .{ }^{16}$

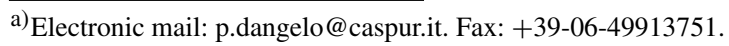

X-ray absorption spectroscopy (XAS) is a short-rangeorder technique that may be a sound tool to gain information on ILs by directly probing the local atomic structure around a selected atom. The advantages of XAS are now well recognized for the analysis of amorphous or liquid media, ${ }^{17-29}$ although relatively few papers have been devoted to the structural investigation of ILs by this technique. ${ }^{30}$ Due to its short-range character this technique can be applied both to the solid and liquid state thus allowing the investigation of ILs in both aggregation states. Here, we present a XAS investigation of imidazolium-based ILs, namely, 1-alkyl-3-methylimidazolium bromide, aimed at elucidating the structural changes that take place around the $\mathrm{Br}^{-}$ion when the alkyl chain length is modified.

\section{EXPERIMENTAL SECTION}

\section{A. X-absorption measurements}

The $\left[\mathrm{C}_{n} \operatorname{mim}\right] \mathrm{Br}$ (with $n=2,4,6,8,10$ ) and 1-butyl-2,3dimethylimidazolium bromide $\left[\mathrm{C}_{4} \operatorname{dimim}\right] \mathrm{Br}$ ILs were purchased from Iolitec $\mathrm{GmbH}$ with a stated purity of $>99 \%$. All ILs were dried in vacuum for about $36 \mathrm{~h}$. The water content was then determined by Karl-Fischer titration and was found to be between 150 and $300 \mathrm{ppm}$ for the different samples. Further purification was not carried out.

The $\mathrm{Br}$ K-edge XAS spectra of solid $\left[\mathrm{C}_{2} \mathrm{mim}\right] \mathrm{Br}$, $\left[\mathrm{C}_{4} \mathrm{mim}\right] \mathrm{Br}$, and $\left[\mathrm{C}_{4}\right.$ dimim $] \mathrm{Br}$ were collected at RT in transmission mode at the Elettra Synchrotron (Trieste, Italy) on the beamline 11.1. The samples were diluted with boron nitride to give an absorption change over the edge of about one logarithmic unit. The storage ring was operating at $2 \mathrm{GeV}$ with an optimal storage beam current between 300 and $130 \mathrm{~mA}$. The 
melting point of $\left[\mathrm{C}_{2} \mathrm{mim}\right] \mathrm{Br}$ and $\left[\mathrm{C}_{4} \mathrm{mim}\right] \mathrm{Br}$ is about $75^{\circ} \mathrm{C}$ (Ref. 31) and to check that the samples were solids and not supercooled liquids, angle-dispersive x-ray diffraction measurements were performed simultaneously with the XAS data collection. The powder diffraction patterns showed that the samples were in a crystalline state. The entrance dose rate was $250 \mathrm{mSv} / \mathrm{s}$ and with this low $\mathrm{x}$-ray dose the samples did not decompose. Moreover, no discoloration of the compounds was observed after data collection. The XAS spectra of liquid $\left[\mathrm{C}_{n} \operatorname{mim}\right] \mathrm{Br}$ with $n=6,8$, and 10 were recorded in transmission mode at the beam-line BM30B French Absorption Spectroscopy Beamline in Material and Environmental Sciences (FAME) at European Synchrotron Radiation Facility. The samples were kept in cells with Kapton film windows and teflon spacers of $0.5 \mathrm{~mm}$. The storage ring was running in the two-third filling mode with a typical current of $170 \mathrm{~mA}$.

\section{B. EXAFS data analysis}

The EXAFS data analysis has been performed using the GNXAS method, which is based on the theoretical calculation of the X-ray absorption fine structure signal and a subsequent refinement of the structural parameters. The theoretical framework of the GNXAS method is described in detail in previous publications. ${ }^{32,33}$ In the GNXAS approach, the interpretation of the experimental data is based on the decomposition of the $\chi(k)$ signal into a summation over $n$-body distribution functions $\gamma^{(n)}$ calculated by means of the multiple scattering (MS) theory. Phase shifts are calculated by using muffin-tin potentials and advanced models for the exchangecorrelation self-energy (Hedin-Lundqvist). Inelastic losses of the photoelectron in the final state are accounted for intrinsically by complex potential.

Starting from the crystallographic structures of $\left[\mathrm{C}_{2} \mathrm{mim}\right] \mathrm{Br},{ }^{34}\left[\mathrm{C}_{4} \mathrm{mim}\right] \mathrm{Br},{ }^{36}$ and $\left[\mathrm{C}_{4} \mathrm{dimim}\right] \mathrm{Br},{ }^{37}$ we have calculated all possible scattering paths within a distance of $4 \AA$ from the $\mathrm{Br}^{-}$ion. All the two-body single-scattering terms have been included, while the MS signals have been found to provide a negligible contribution. Previous works dealing with the analysis of the EXAFS spectra of $\mathrm{Br}^{-}$in aqueous solution have shown that the hydrogen atoms of the $\mathrm{Br}^{-}$first hydration shell provide a detectable contribution. ${ }^{38-40}$ For this reason here we have included all of the $\mathrm{Br}-\mathrm{H}$ signals at distances shorter than $3 \AA$.

The EXAFS data analysis of all our samples has been performed generating a model spectrum starting from the crystallographic structures by adding all the relevant contributions. The model $\chi(k)$ signal was then refined against the experimental data by using a least-squares minimization procedure in which structural and nonstructural parameters were allowed to float. The structural parameters were the bond distance $(\mathrm{R})$ and bond variance $\left(\sigma^{2}\right)$ for each twobody signal, while coordination numbers were fixed at the known crystallographic values. Two nonstructural parameters were minimized, namely, $E_{0}$ (core ionization threshold) and $S_{0}^{2}$ (many body amplitude reduction factor). The quality of the fits was determined by the goodness-of-the-fit parameter. $^{32,33}$

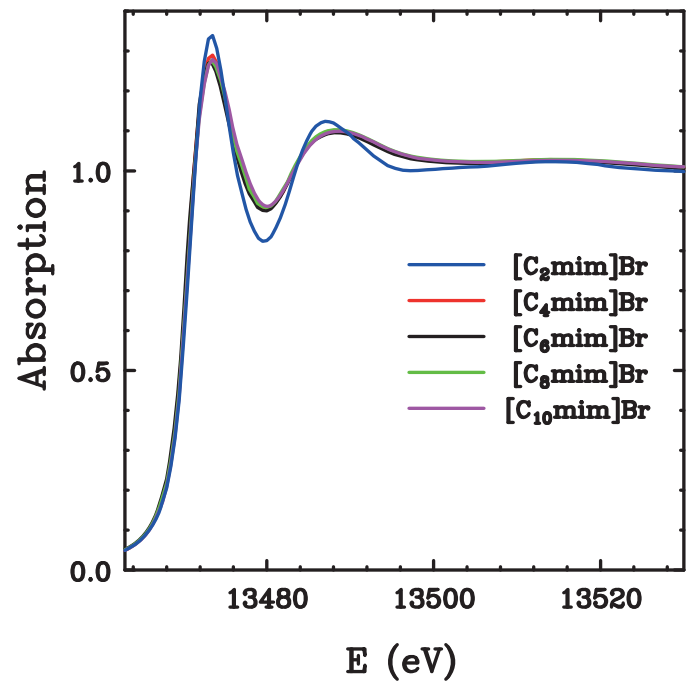

FIG. 1. Br K-edge $\mathrm{x}$-ray absorption spectra of the $\left[\mathrm{C}_{n} \mathrm{mim}\right] \mathrm{Br}$ ILs under ambient conditions, $\left[\mathrm{C}_{2} \mathrm{mim}\right] \mathrm{Br}$ and $\left[\mathrm{C}_{4} \mathrm{mim}\right] \mathrm{Br}$ are solid, while the other compounds are liquid at RT.

\section{RESULTS AND DISCUSSION}

\section{A. EXAFS analysis of $\left[\mathrm{C}_{n}\right.$ mim]Br ILs}

The $\mathrm{Br}$ K-edge XAS spectra of $\left[\mathrm{C}_{n} \mathrm{mim}\right] \mathrm{Br}$ (with $n$ $=2,4,6,8,10$ ) collected at $300 \mathrm{~K}$ are shown in Fig. 1. Note that the first two members of the series, namely, $\left[\mathrm{C}_{2} \mathrm{mim}\right] \mathrm{Br}$ and $\left[\mathrm{C}_{4} \mathrm{mim}\right] \mathrm{Br}$ are solid at $\mathrm{RT}$, while the other compounds are liquid. It can be seen that while for $n \geq 4$ the spectra are identical, the $\left[\mathrm{C}_{2} \mathrm{mim}\right] \mathrm{Br}$ spectrum shows significant differences in all the energy range. The similarity of the XAS features gives a first indication that, despite their aggregation state, the local coordination around $\mathrm{Br}^{-}$is identical in all of the investigated ILs, with the exception of $\left[\mathrm{C}_{2} \mathrm{mim}\right] \mathrm{Br}$ in which the anion shows a different environment.

These results are confirmed by the EXAFS spectra extracted with a three segmented cubic spline and the corresponding Fourier transform calculated in the interval $k=2.0$ $8.0 \AA^{-1}$, with no phase shift correction applied, shown in the upper and lower panels of Fig. 2, respectively. As already observed for the x-ray absorption near-edge structure (XANES) data, both the EXAFS and FT signals of the $\left[\mathrm{C}_{2}\right.$ mim]Br are different from those of the other members of the series that show almost identical EXAFS and FT spectra. In particular, the amplitude of the EXAFS spectrum of $\left[\mathrm{C}_{2} \mathrm{mim}\right] \mathrm{Br}$ is larger as compared to the other ILs and the corresponding FT is characterized by a higher intensity first shell peak located at slightly longer distances.

An important piece of information on ILs which is probed by XAS with high sensitivity is the short range order around the $\mathrm{Br}^{-}$ions and this insight is not achievable by any other experimental technique. A meaningful comparison can be made with the short range order displayed in the corresponding crystal structures.

The crystal structure of $\left[\mathrm{C}_{2} \mathrm{mim}\right] \mathrm{Br}$ indicates that anions and cations are interconnected by an extended network of hydrogen bonds. ${ }^{34}$ Hydrogen-anion contacts dominate the interactions and each bromide is in close contact with six hydrogen 

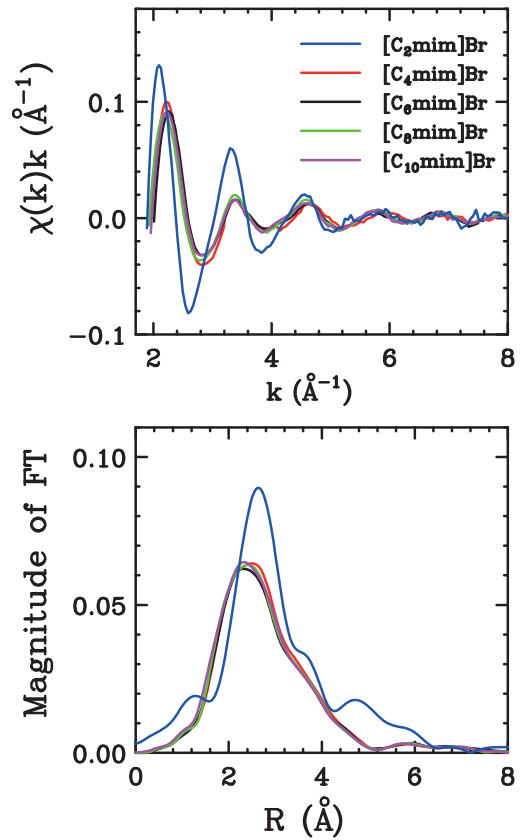

FIG. 2. EXAFS and corresponding Fourier transform spectra of $\left[\mathrm{C}_{n} \mathrm{mim}\right] \mathrm{Br}$ ILs at RT.

atoms, three bromide-ring hydrogen atom contacts are found at $2.78 \AA\left(\mathrm{H}(2)-\mathrm{Br}^{-}\right), 2.89 \AA\left(\mathrm{H}(4)-\mathrm{Br}^{-}\right)$, and $2.97 \AA(\mathrm{H}(5)-$ $\left.\mathrm{Br}^{-}\right)$, and the methyl hydrogen-bromide contacts are at about $3 \AA$ (see Fig. 3(a)). The $\mathrm{H}(4)-\mathrm{Br}^{-}$and $\mathrm{H}(5)-\mathrm{Br}^{-}$contacts are slightly longer than $\mathrm{H}(2)-\mathrm{Br}^{-}$indicating that the strongest hydrogen bond takes place with the most acidic hydrogen atom of the ring. As evident from the crystal structure (see Fig. 1S in supplementary material ${ }^{35}$ ), the cations are not aligned in layers but give rise to pockets that accommodate the $\mathrm{Br}^{-}$ion allowing the formation of an extensive cation-anion hydrogen bonding pattern.

In comparison to the extensive hydrogen-bonding interactions observable in $\left[\mathrm{C}_{2} \mathrm{mim}\right] \mathrm{Br}$, the crystal structure of $\left[\mathrm{C}_{4} \mathrm{mim}\right] \mathrm{Br}$ shows only one hydrogen-bond contact between the anion and the $\mathrm{H}(2)$ imidazolium atom at $2.45 \AA$ (see Fig. 3(b)). The $\mathrm{Br}^{-}$ion is placed in the plane of the imidazolium ring and the interaction between the acidic hydrogen and the bromide atoms is quite strong. The crystal lattice of (a)

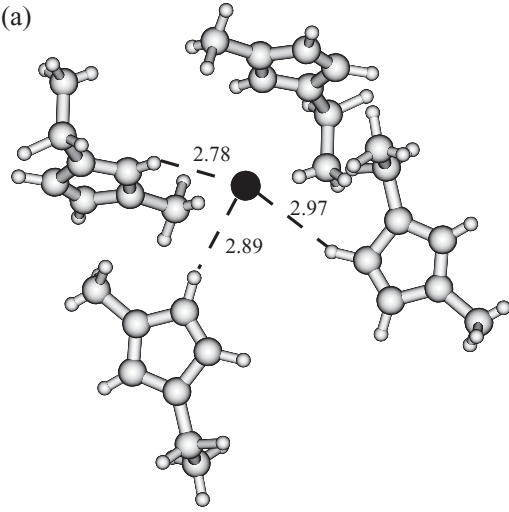

(b)

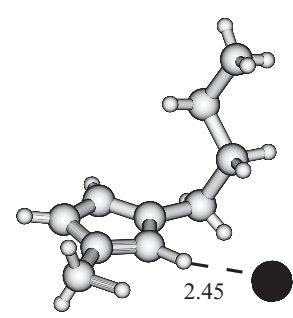

FIG. 3. Local coordination around a single bromide ion in the crystal structures of $\left[\mathrm{C}_{2} \operatorname{mim}\right] \mathrm{Br}$ (a) and $\left[\mathrm{C}_{4} \mathrm{mim}\right] \mathrm{Br}(\mathrm{b})$.

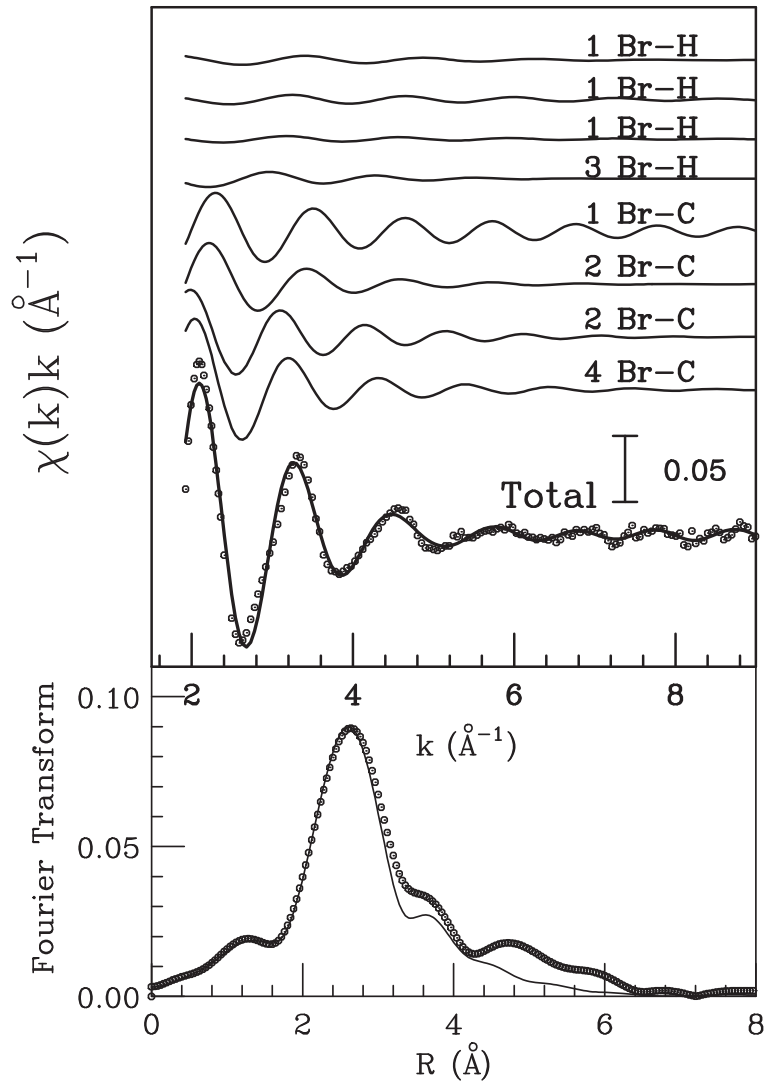

FIG. 4. Upper panel: Fit of the EXAFS spectrum of solid $\left[\mathrm{C}_{2} \mathrm{mim}\right] \mathrm{Br}$. From the top to the bottom we report the $\mathrm{Br}-\mathrm{H}$ and $\mathrm{Br}-\mathrm{C}$ theoretical signals and the total theoretical signal (solid line) compared to the experimental spectrum (dotted line). Lower panel: Non-phase-shift corrected Fourier transforms of EXAFS experimental data (dotted line) and the theoretical signal (solid line) of solid $\left[\mathrm{C}_{2} \mathrm{mim}\right] \mathrm{Br}$.

$\left[\mathrm{C}_{4}\right.$ mim $] \mathrm{Br}$ (see Fig. $2 \mathrm{~S}$ in supplementary material ${ }^{35}$ ) consists of alternating two-dimensional sheets where the imidazolium head groups are planar and the alkyl side chains adopt an all trans conformation. Both the orientation of the cations and the alkyl chain alternate so that a bilayer structure is formed. The lattice is stabilized by $\pi-\pi$ stacking interactions between the aromatic rings, by van der Waals interactions between the alkyl chains, and by the hydrogen bond between the $\mathrm{Br}^{-}$ion and the $\mathrm{H}(2)$ atom. The shortest $\mathrm{Br}-\mathrm{Br}$ distances are 4.77, 6.55, and $8.30 \AA$ and are all longer than the sum of the van der Waals radii (3.7 $\AA$ ). This fact indicates that there are no specific interactions among the $\mathrm{Br}^{-}$anions.

The EXAFS data analysis of solid $\left[\mathrm{C}_{2} \mathrm{mim}\right] \mathrm{Br}$ has been performed starting from the coordination geometry of the $\mathrm{Br}^{-}$ ion obtained from the crystallographic structure. In particular, we included 3 hydrogen atoms at 2.78, 2.89, and $2.97 \AA$, plus three additional $\mathrm{Br}-\mathrm{H}$ contacts at $3.0 \AA$. The first $\mathrm{C}$ atom lies at a distance of $3.57 \AA$ from the $\mathrm{Br}^{-}$ion, and eight $\mathrm{Br}-\mathrm{C}$ contacts are present up to $3.9 \AA$. Least-squares fits of the EXAFS spectrum have been performed in the range of $k=2.0$ $-9.0 \AA^{-1}$. In Fig. 4 we show all the $\mathrm{Br}-\mathrm{H}$ and $\mathrm{Br}-\mathrm{C}$ theoretical signals that have been included in the analysis. Note that the $\mathrm{Br}-\mathrm{H}$ signals provide a detectable contribution to the EXAFS spectrum. Fitting procedures have been applied to the whole set of structural and nonstructural parameters to improve, as 
TABLE I. Crystallographic structure and EXAFS results for $\left[\mathrm{C}_{2} \mathrm{mim}\right] \mathrm{Br}$.

\begin{tabular}{|c|c|c|c|}
\hline & $\mathrm{N}$ & $\begin{array}{c}\mathrm{R} \\
(\AA)\end{array}$ & $\begin{array}{c}\sigma^{2} \\
\left(\AA^{2}\right)\end{array}$ \\
\hline$\left[\mathrm{C}_{2} \mathrm{mim}\right] \mathrm{Br}$ & $1 \mathrm{H}$ & 2.78 & \\
\hline \multirow[t]{7}{*}{ Crystal structure } & $1 \mathrm{H}$ & 2.89 & \\
\hline & $1 \mathrm{H}$ & 2.97 & \\
\hline & $3 \mathrm{H}$ & 3.00 & \\
\hline & $1 \mathrm{C}$ & 3.57 & \\
\hline & $2 \mathrm{C}$ & 3.73 & \\
\hline & $2 \mathrm{C}$ & 3.84 & \\
\hline & $4 \mathrm{C}$ & 3.90 & \\
\hline$\left[\mathrm{C}_{2} \mathrm{mim}\right] \mathrm{Br}$ & $1 \mathrm{H}$ & $2.79(2)$ & $0.02(1)$ \\
\hline \multirow[t]{7}{*}{ EXAFS } & $1 \mathrm{H}$ & $2.90(2)$ & $0.02(1)$ \\
\hline & $1 \mathrm{H}$ & $2.98(3)$ & $0.02(1)$ \\
\hline & $3 \mathrm{H}$ & $3.05(3)$ & $0.04(1)$ \\
\hline & $1 \mathrm{C}$ & $3.58(2)$ & $0.02(1)$ \\
\hline & $2 \mathrm{C}$ & $3.73(2)$ & $0.03(1)$ \\
\hline & $2 \mathrm{C}$ & $3.85(3)$ & $0.02(1)$ \\
\hline & $4 \mathrm{C}$ & $3.95(3)$ & $0.05(2)$ \\
\hline
\end{tabular}

far as possible, the agreement between the calculated signals and the experimental spectra. The full list of structural parameters obtained from the EXAFS data analysis is reported in Table I and the results are shown in Fig. 4. From the minimization procedure $E_{0}$ was found to be $1 \mathrm{eV}$ above the first inflection point of the spectrum, while $S_{0}^{2}$ was found equal to 1 .

The statistical errors have been estimated by looking at the confidence intervals in the parameters' space. Standard deviations and correlation effects have been obtained from the correlation maps determined for each couple of parameters. The estimated statistical errors associated with the 95\% confidence interval have been obtained as described in Ref. 32. A very good agreement between the theoretical signal and the experimental spectrum has been obtained thus proving the reliability of the data analysis scheme. Note that the best-fit structural parameters obtained from the EXAFS analysis match very closely the crystallographic determination.

A deeper insight into the differences observed between the EXAFS data of solid $\left[\mathrm{C}_{2} \mathrm{mim}\right] \mathrm{Br}$ and $\left[\mathrm{C}_{4} \mathrm{mim}\right] \mathrm{Br}$ has been gained from the analysis of the butyl derivative spectrum. A theoretical signal has been calculated starting from the crystallographic structure and it comprises of one hydrogen atom at $2.45 \AA$ plus five hydrogen atoms at $3.0 \AA$. The shortest $\mathrm{Br}-\mathrm{C}$ distance is $3.51 \AA$, while eight additional $\mathrm{C}$ atoms are found up to $3.9 \AA$. Minimization procedures have been carried out in the range of $k=2.0-9.0 \AA^{-1}$ and the results of the EXAFS analysis are shown in panel (a) of Fig. 5. The best-fit structural parameters are listed in Table II and the theoretical curve matches very closely the experimental signal. Also in this case $E_{0}$ was found to be $1 \mathrm{eV}$ above the first inflection point of the spectrum, while $S_{0}^{2}$ was found equal to 1 . All of the $\mathrm{Br}-\mathrm{H}$ and $\mathrm{Br}-\mathrm{C}$ theoretical signals included in the analysis are shown in Fig. $3 \mathrm{~S}$ of supplementary material. ${ }^{35}$

An interesting insight into the mobility of the $\mathrm{Br}^{-}$ion in the two crystals can be gained by looking at the Debye-Waller factors obtained from the EXAFS analyses of the two solid

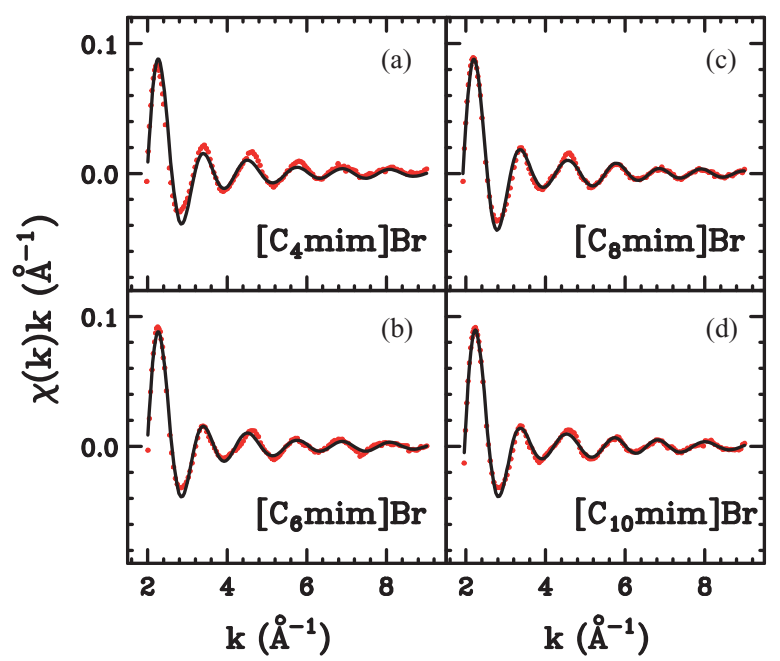

FIG. 5. Fit of the $\mathrm{Br}$ K-edge EXAFS spectrum of $\left[\mathrm{C}_{4} \mathrm{mim}\right] \mathrm{Br}$ crystal (a), liquid $\left[\mathrm{C}_{6} \mathrm{mim}\right] \mathrm{Br}(\mathrm{b})$, liquid $\left[\mathrm{C}_{8} \mathrm{mim}\right] \mathrm{Br}(\mathrm{c})$, and liquid $\left[\mathrm{C}_{10} \mathrm{mim}\right] \mathrm{Br}(\mathrm{d})$. The experimental data are in red dotted line and the fitted theoretical signal is the black full line.

samples listed in Tables I and II. As previously mentioned, the amplitude of both the EXAFS and FT signals is bigger for $\left[\mathrm{C}_{2}\right.$ mim $] \mathrm{Br}$ than for $\left[\mathrm{C}_{4} \mathrm{mim}\right] \mathrm{Br}$; as the total number of coordinated $\mathrm{H}$ and $\mathrm{C}$ atoms is the same in the two samples, the higher intensity of the EXAFS oscillation of the ethyl derivative is due to the lower thermal vibration of the $\mathrm{Br}^{-}$ion in this sample. This behaviour is reflected in the Debye-Waller factor values that are systematically lower in the ethyl derivative as compared to the butyl one. This finding is in agreement with the existence of a higher number of hydrogen-bonding interactions in $\left[\mathrm{C}_{2} \mathrm{mim}\right] \mathrm{Br}$ that make the $\mathrm{Br}^{-}$ion more constrained in the crystal as compared to $\left[\mathrm{C}_{4} \mathrm{mim}\right] \mathrm{Br}$, where the hydrogen bond network is less extended and the crystal lattice is mainly stabilized by $\pi-\pi$ interactions and van der Waals forces.

In the second step of the analysis we used the crystal geometry of $\left[\mathrm{C}_{4} \mathrm{mim}\right] \mathrm{Br}$ to fit the EXAFS spectra of the ILs

TABLE II. Crystallographic structure of $\left[\mathrm{C}_{4} \mathrm{mim}\right] \mathrm{Br}$ and EXAFS results for $\left[\mathrm{C}_{4} \mathrm{mim}\right] \mathrm{Br},\left[\mathrm{C}_{6} \mathrm{mim}\right] \mathrm{Br},\left[\mathrm{C}_{8} \mathrm{mim}\right] \mathrm{Br}$, and $\left[\mathrm{C}_{10} \mathrm{mim}\right] \mathrm{Br}$.

\begin{tabular}{|c|c|c|c|c|c|c|}
\hline & & $\begin{array}{c}{\left[\mathrm{C}_{4} \operatorname{mim}\right] \mathrm{Br}} \\
\text { (crystal) }\end{array}$ & $\begin{array}{c}\left.\mathrm{C}_{4} \mathrm{mim}\right] \mathrm{B} \\
\text { EXAFS }\end{array}$ & $\begin{array}{c}\left.\mathrm{C}_{6} \mathrm{mim}\right] \mathrm{Br} \\
\text { EXAFS }\end{array}$ & $\begin{array}{c}\left.\mathrm{C}_{8} \operatorname{mim}\right] \mathrm{B}_{1} \\
\text { EXAFS }\end{array}$ & $\begin{array}{c}\left.\mathrm{C}_{10} \mathrm{mim}\right] \mathrm{Br} \\
\text { EXAFS }\end{array}$ \\
\hline \multirow[t]{2}{*}{$1 \mathrm{H}$} & $\mathrm{R}(\AA)$ & 2.44 & $2.42(2)$ & 2.43(2) & $2.43(2)$ & $2.42(2)$ \\
\hline & $\sigma^{2}\left(\AA^{2}\right)$ & & $0.04(1)$ & $0.04(1)$ & $0.04(1)$ & $0.04(1)$ \\
\hline \multirow[t]{2}{*}{$6 \mathrm{H}$} & $\mathrm{R}(\AA)$ & 3.00 & $3.09(2)$ & $3.09(2)$ & $3.09(2)$ & $3.09(2)$ \\
\hline & $\sigma^{2}\left(\AA^{2}\right)$ & & $0.06(2)$ & $0.06(2)$ & $0.06(2)$ & $0.06(2)$ \\
\hline \multirow[t]{2}{*}{$1 \mathrm{C}$} & $\mathrm{R}(\AA)$ & 3.51 & $3.53(3)$ & $3.53(3)$ & $3.54(3)$ & $3.53(3)$ \\
\hline & $\sigma^{2}\left(\AA^{2}\right)$ & & $0.03(1)$ & $0.03(1)$ & $0.03(1)$ & $0.03(1)$ \\
\hline \multirow[t]{2}{*}{$2 \mathrm{C}$} & $\mathrm{R}(\AA)$ & 3.66 & $3.67(3)$ & $3.66(3)$ & $3.66(3)$ & $3.67(3)$ \\
\hline & $\sigma^{2}\left(\AA^{2}\right)$ & & $0.06(2)$ & $0.06(2)$ & $0.06(2)$ & $0.06(2)$ \\
\hline \multirow[t]{2}{*}{$1 \mathrm{C}$} & $\mathrm{R}(\AA ̊)$ & 3.73 & $3.76(3)$ & $3.75(3)$ & $3.75(3)$ & $3.76(3)$ \\
\hline & $\sigma^{2}\left(\AA^{2}\right)$ & & $0.05(2)$ & $0.05(2)$ & $0.05(2)$ & $0.05(2)$ \\
\hline \multirow[t]{2}{*}{$3 \mathrm{C}$} & $\mathrm{R}(\AA)$ & 3.82 & $3.83(3)$ & $3.83(3)$ & $3.83(3)$ & $3.83(3)$ \\
\hline & $\sigma^{2}\left(\AA^{2}\right)$ & & $0.07(2)$ & $0.07(2)$ & $0.07(2)$ & $0.07(2)$ \\
\hline \multirow[t]{2}{*}{$2 \mathrm{C}$} & $\mathrm{R}(\AA)$ & 3.88 & $3.90(3)$ & $3.90(3)$ & $3.91(3)$ & $3.90(3)$ \\
\hline & $\sigma^{2}\left(\AA^{2}\right)$ & & $0.06(2)$ & $0.06(2)$ & $0.06(2)$ & $0.06(2)$ \\
\hline
\end{tabular}


with longer alkyl chains that are liquid at RT. The minimization procedures were carried out using the same strategy previously described and the best-fit results of the $\left[\mathrm{C}_{6} \mathrm{mim}\right] \mathrm{Br}$, $\left[\mathrm{C}_{8} \mathrm{mim}\right] \mathrm{Br}$, and $\left[\mathrm{C}_{10} \mathrm{mim}\right] \mathrm{Br}$ ILs are shown in panels (b), (c), and (d) of Fig. 5, respectively, while the structural parameters are listed in Table II. In all cases a very good agreement has been obtained between the experimental spectra and the theoretical signals associated with the $\left[\mathrm{C}_{4} \mathrm{mim}\right] \mathrm{Br}$ crystal structure. This finding definitely proves that the local structure of the $\mathrm{Br}^{-}$ion in the liquid ILs is the same as that of solid $\left[\mathrm{C}_{4} \mathrm{mim}\right] \mathrm{Br}$, despite the length of the alkyl chain.

\section{B. EXAFS analysis of $\left[\mathrm{C}_{4}\right.$ dimim $] \mathrm{Br}$}

The last step of our investigation was aimed at unveiling the sensitivity of the XAS technique towards the coordination environment of the photoabsorber, in particular, with regard to the modification of the hydrogen bond network. To this end we focused on the structural modification of the $\mathrm{Br}^{-}$environment induced by the methylation at the position 2 of the cation ring. As previously shown, the $\mathrm{H}(2)$ proton of the imidazolium ring strongly interacts with the anion and the methylation of the position 2 causes significant changes in the physicochemical properties of these ILs. A recent Raman study on solid and liquid $\left[\mathrm{C}_{4} \operatorname{dimim}\right] \mathrm{Br}$ showed that there is a change of the anion position relative to the cation following the methylation. ${ }^{41}$ In particular, in the methylated sample the $\mathrm{Br}^{-}$ ion is situated closer to the protons at the positions 4 and 5 of the ring as compared to the $\left[\mathrm{C}_{4} \mathrm{mim}\right] \mathrm{Br}$ compound. ${ }^{37}$ This result is confirmed by the crystal structure of solid $\left[\mathrm{C}_{4} \operatorname{dimim}\right] \mathrm{Br}$ showing that the anion is in close contact with three hydrogen atoms at $2.73 \AA\left(\mathrm{H}(5)-\mathrm{Br}^{-}\right), 2.82 \AA\left(\mathrm{H}(4)-\mathrm{Br}^{-}\right)$, and $2.86 \AA$ (methyl hydrogen) (see Fig. 6). Note that this geometry is very similar to the $\left[\mathrm{C}_{2} \mathrm{mim}\right] \mathrm{Br}$ one, and also the crystal structure (see Fig. $4 \mathrm{~S}$ in supplementary material ${ }^{35}$ ) shows a molecular arrangement very different from that of the unmethylated analogs. ${ }^{37}$ Here, we collected the XAS spectrum at the $\mathrm{Br}$ K-edge of $\left[\mathrm{C}_{4} \operatorname{dimim}\right] \mathrm{Br}$ at $\mathrm{RT}$. The XANES data, the EXAFS spectrum extracted with a three segmented cubic spline, and the FT signal calculated in the interval $k=2.0$ $-8.0 \AA^{-1}$ of $\left[\mathrm{C}_{4}\right.$ dimim $] \mathrm{Br}$ are compared to those of the unmethylated analogs in Fig. 7. The XANES spectra of

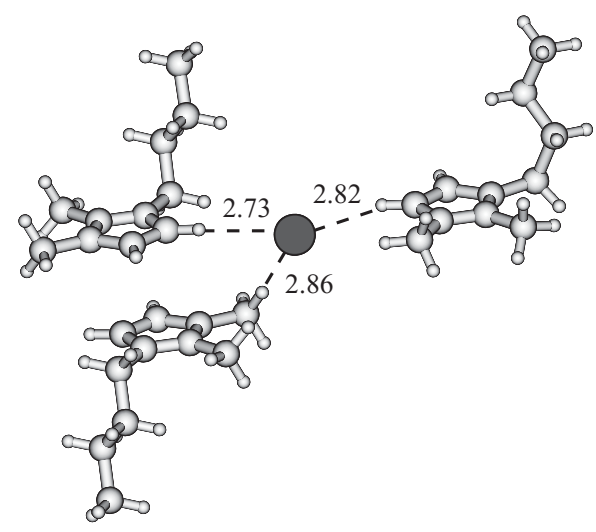

FIG. 6. Local coordination around a single bromide ion in the crystal structure of $\left[\mathrm{C}_{4}\right.$ dimim $] \mathrm{Br}$.
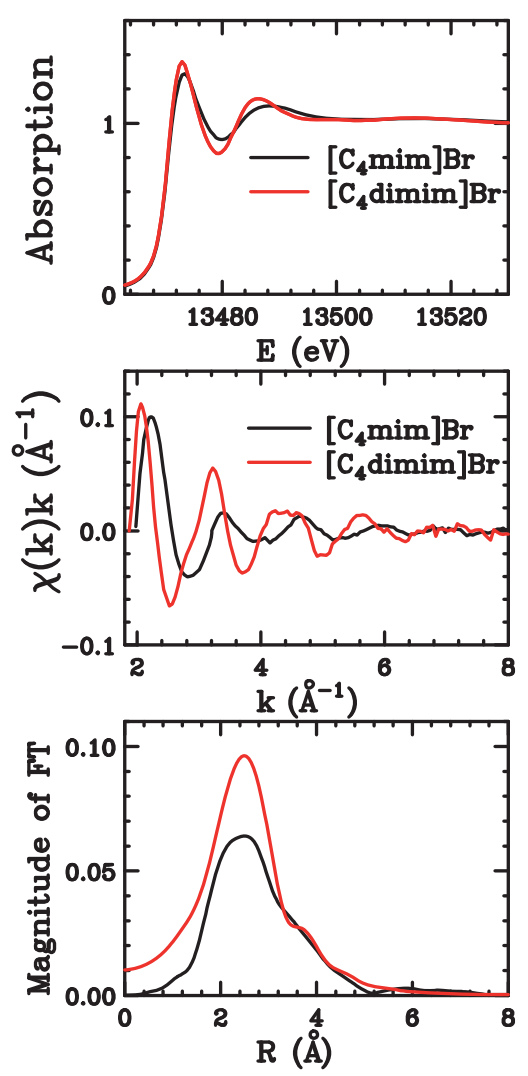

FIG. 7. Upper panel: $\mathrm{Br} \mathrm{K}$-edge $\mathrm{x}$-ray absorption spectra of $\left[\mathrm{C}_{4} \operatorname{mim}\right] \mathrm{Br}$ (black line) and $\left[\mathrm{C}_{4}\right.$ dimim $] \mathrm{Br}$ (red line) under ambient conditions. EXAFS and corresponding magnitude of Fourier transform spectra are shown in the middle and lower panels, respectively.

$\left[\mathrm{C}_{4} \mathrm{mim}\right] \mathrm{Br}$ and $\left[\mathrm{C}_{4}\right.$ dimim $] \mathrm{Br}$ are markedly different, the EXAFS and FT signals of the latter compound show a higher amplitude and the position of the FT peak is shifted towards longer distances. Note that the $\left[\mathrm{C}_{4} \mathrm{dimim}\right] \mathrm{Br}$ spectra are very similar to those of $\left[\mathrm{C}_{2} \mathrm{mim}\right] \mathrm{Br}$ as upon methylation the $\mathrm{Br}^{-}$experiences a local coordination geometry similar to that found in $\left[\mathrm{C}_{2} \mathrm{mim}\right] \mathrm{Br}$ (see Figs. 3(a) and 6) with hydrogen-bonding contacts with $\mathrm{H}(4)$ and $\mathrm{H}(5)$, as previously determined from the Raman investigation. ${ }^{41}$ Also, in

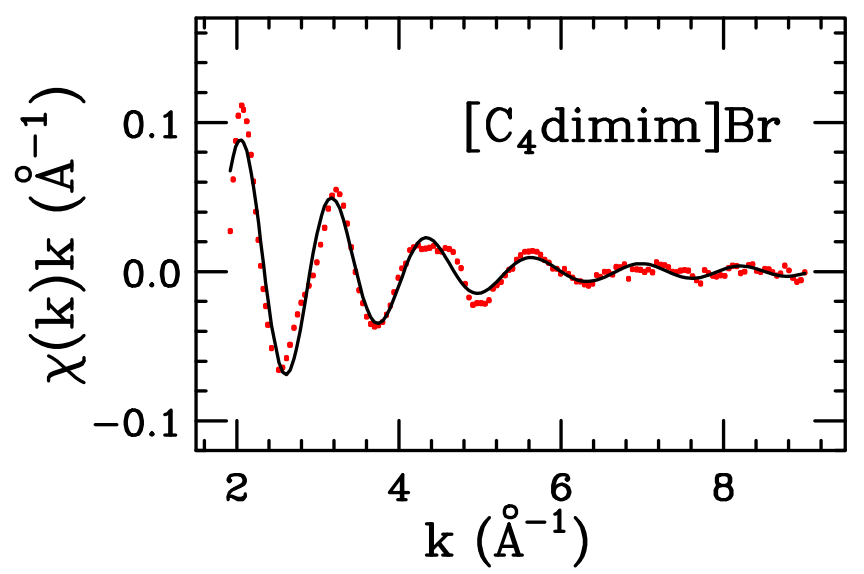

FIG. 8. Fit of the Br K-edge EXAFS spectrum of $\left[\mathrm{C}_{4}\right.$ dimim $] \mathrm{Br}$ crystal. The experimental data are in red dotted line and the theoretical signal is the black full line. 
TABLE III. Crystallographic structure and EXAFS results for $\left[\mathrm{C}_{4}\right.$ dimim $] \mathrm{Br}$.

\begin{tabular}{|c|c|c|c|}
\hline & $\mathrm{N}$ & $\begin{array}{c}\mathrm{R} \\
(\AA)\end{array}$ & $\begin{array}{c}\sigma^{2} \\
\left(\AA^{2}\right)\end{array}$ \\
\hline$\left[\mathrm{C}_{4} \operatorname{dimim}\right] \mathrm{Br}$ & $1 \mathrm{H}$ & 2.73 & \\
\hline \multirow[t]{7}{*}{ Crystal structure } & $1 \mathrm{H}$ & 2.82 & \\
\hline & $1 \mathrm{H}$ & 2.86 & \\
\hline & $3 \mathrm{H}$ & 2.93 & \\
\hline & $3 \mathrm{C}$ & 3.67 & \\
\hline & $1 \mathrm{C}$ & 3.74 & \\
\hline & $1 \mathrm{C}$ & 3.82 & \\
\hline & $3 \mathrm{C}$ & 3.92 & \\
\hline$\left[\mathrm{C}_{4} \operatorname{dimim}\right] \mathrm{Br}$ & $1 \mathrm{H}$ & $2.76(3)$ & $0.02(1)$ \\
\hline \multirow[t]{7}{*}{ EXAFS } & $1 \mathrm{H}$ & $2.83(3)$ & $0.02(1)$ \\
\hline & $1 \mathrm{H}$ & $2.86(3)$ & $0.02(1)$ \\
\hline & $3 \mathrm{H}$ & $2.94(4)$ & $0.04(2)$ \\
\hline & $3 \mathrm{C}$ & $3.68(3)$ & $0.03(1)$ \\
\hline & $1 \mathrm{C}$ & $3.73(3)$ & $0.02(1)$ \\
\hline & $1 \mathrm{C}$ & $3.84(4)$ & $0.02(1)$ \\
\hline & $3 \mathrm{C}$ & $3.95(4)$ & $0.05(3)$ \\
\hline
\end{tabular}

this case the higher intensity of the EXAFS and FT spectra of $\left[\mathrm{C}_{4}\right.$ dimim $] \mathrm{Br}$ as compared to $\left[\mathrm{C}_{4} \mathrm{mim}\right] \mathrm{Br}$ is due to the lower thermal vibration of the $\mathrm{Br}^{-}$ion in the crystal lattice of the former sample where the anion is involved in a more extended hydrogen bond network. This finding is confirmed by the quantitative analysis of the EXAFS spectrum of $\left[\mathrm{C}_{4}\right.$ dimim $] \mathrm{Br}$ that has been carried out starting from the crystal geometry. The results of this analysis are shown in Fig. 8 and the optimized structural parameters are listed in Table III. Once more the theoretical EXAFS signal is in very good agreement with the experimental data and the Debye-Waller values obtained from the minimization procedure are similar to those found for $\left[\mathrm{C}_{2} \mathrm{mim}\right] \mathrm{Br}$. Alltogether, the results of the present analysis testify the sensitivity and the potentiality of the XAS technique in the structural investigation of selected ionic liquids.

\section{DISCUSSION AND CONCLUSIONS}

In this study the XAS technique has been used to unveil the $\mathrm{Br}^{-}$local coordination structure in imidazoliumbased ILs. The similarity of the XAS spectra of the 1-alkyl-3methylimidazolium bromide salts, from the butyl to the decyl derivatives, revealed that the molecular organization present in the $\left[\mathrm{C}_{4} \mathrm{mim}\right] \mathrm{Br}$ crystal phase is maintained also in the liquids at a local level, and the arrangement of the imidazolium head groups around the $\mathrm{Br}^{-}$ion is the same independently from the length of the alkyl chain. Note that the existence of ordered local structures in liquid $\left[\mathrm{C}_{4} \mathrm{mim}\right] \mathrm{Br}$ was previously pointed out in a work based on Raman and x-ray diffraction data. ${ }^{16}$

The investigation of $\left[\mathrm{C}_{4}\right.$ dimim $] \mathrm{Br}$ where the acidic $\mathrm{H}(2)$ atom is replaced by a methyl group allowed us to test the sensitivity of the XAS technique towards small changes of the $\mathrm{Br}^{-}$environment. Detectable differences were found between the XAS spectra of the methylated and unmethylated derivatives steaming from the different hydrogen bond network involving the $\mathrm{Br}^{-}$ion. The identical environment of the $\mathrm{Br}^{-}$ ion in $\left[\mathrm{C}_{n}\right.$ mim $] \mathrm{Br}$ with $n \geq 4$ indicates that the imidazolium head groups in the liquid ILs assume locally the same orientation as in the $\left[\mathrm{C}_{4} \mathrm{mim}\right] \mathrm{Br}$ crystal giving rise to $\pi-\pi$ interactions. The stacking of the head groups forces the alkyl chains to adopt a quite regular arrangement aimed at maximizing the van der Waals interactions. Moreover, the existence of an identical amplitude in the EXAFS spectra of the solid and liquids indicates that the structural disorder in the two phases is similar. As a result we can conclude that the orientational order present in the crystalline lattice is locally preserved in the liquid. The presence of such an orientational order gives rise to many unique properties of ILs, such as unusually high viscosity ascribable to the local structures that hinder the translational motion of the ions. Moreover, the amphiphilic character and the corresponding separation between the hydrophobic alkyl tails and the hydrophilic imidazolium rings explains the capability of ILs to dissolve both polar and nonpolar solutes.

In conclusion, use of the XAS technique allowed us to unveil the structural arrangement around the $\mathrm{Br}^{-}$ion in $\left[\mathrm{C}_{n} \mathrm{mim}\right] \mathrm{Br}$ ILs thus providing information that is not easily achievable with other experimental techniques.

\section{ACKNOWLEDGMENTS}

This work was supported by the University of Rome "La Sapienza" (Progetto Protic Ionic Liquids, ateneo 2010) and by CASPUR with the Standard HPC Grant 2011 entitled: "A combined x-ray absorption spectroscopy, molecular dynamics simulations, and quantum mechanics calculation procedure for the structural characterization of ill-defined systems." We acknowledge the European Synchrotron Radiation Facility and Elettra for provision of synchrotron radiation facilities.

${ }^{1} \mathrm{P}$. Wasserscheid and T. Welton, Ionic Liquids in Synthesis (Wiley-VCH, Weinheim, 2008).

${ }^{2}$ A. Stark and K. R. Seddon, "Ionic liquids" in Kirk-Othmer Encyclopaedia of Chemical Technology, edited by A. Seidel, 5th ed. (Wiley, Hoboken, New Jersey, 2007), Vol. 26, pp. 836-920.

${ }^{3} \mathrm{M}$. Freemantle, An Introduction to Ionic Liquids (RSC, Cambridge, UK, 2009) p. 281.

${ }^{4}$ N. V. Plechkova and K. R. Seddon, Chem. Soc. Rev. 37, 123 (2008).

${ }^{5} \mathrm{H}$. Weingartner, Angew. Chem. 47, 654 (2008).

${ }^{6}$ H. Tokuda, K. Hayamizu, K. Ishii, Md. A. B. Hasan Susan, and M. Watanabe, J. Phys. Chem. B 109, 6103 (2005).

${ }^{7}$ Do. Xiao, L. G. Hines, S. Li, R. A. Bartsch, and E. L. Quitevis, J. Phys. Chem. B 113, 6426 (2009).

${ }^{8}$ A. Triolo, O. Russina, H.-J. Bleif, and E. Di Cola, J. Phys. Chem. B 111, 4641 (2007).

${ }^{9}$ S. G. Raju and S. Balasubramanian, J. Phys. Chem. B 113, 4799 (2009).

${ }^{10}$ I. Goodchild, L. Collier, S. L. Millar, I. Prokes, J. C. D. Lord, C. P. Butts, J. Bowers, J. R. Webster, and R. K. Heenan, J. Colloid. Interface. Sci 307, 455 (2007).

${ }^{11}$ N. A. Smirnova, A. A. Vanin, E. A. Safonova, I. B. Pukinsky, Y. A. Anufrikov, and A. L. Makarov, J. Colloid. Interface Sci. 336, 793 (2009).

${ }^{12}$ M. Imanari, K. Uchida, K. Miyano, H. Sekib, and K. Nishikawa, Phys. Chem. Chem. Phys. 12, 2959 (2010).

${ }^{13}$ N. E. Helmer, J. S. Wilkes, P. G. Wahlbeck, and W. R. J. Carper, J. Phys. Chem. A 110, 868 (2006).

${ }^{14}$ A. Triolo, A. Mandanici, O. Russina, V. Rodriguez-Mora, M. Cutroni, C. Hardacre, M. Nieuwenhuyzen, H.-J. Bleif, L. Keller, and M. A. Ramos, J. Phys. Chem. B 110, 21357 (2006). 
${ }^{15}$ C. Hardacre, J. D. Holbrey, S. E. J. McMath, D. T. Bowron, and A. K. Soper, J. Chem. Phys. 118, 273 (2003).

${ }^{16}$ H.-O. Hamaguchi and R. Ozawa, Advances in Chemical Physics (WileyVCH, Berlin, 2005), Vol. 131, p. 85.

${ }^{17}$ H. Ohtaki and T. Radnai, Chem. Rev. 93, 1157 (1993).

${ }^{18}$ P. D'Angelo, A. Di Nola, A. Filipponi, N. V. Pavel, and D. Roccatano, J. Chem. Phys. 100, 985 (1994).

${ }^{19}$ H. Tanida, H. Sakane, and I. Watanabe, J. Chem. Soc. Dalton Trans. 15, 2321 (1994).

${ }^{20}$ L. Campbell, J. J. Rehr, G. K. Schenter, M. I. McCarthy, and D. Dixon, J. Synchrotron Radiat. 6, 310 (1999).

${ }^{21}$ R. Beudert, H. Bertagnolli, and M. Zeller, J. Chem. Phys. 106, 8841 (1997).

${ }^{22}$ S. L. Wallen, B. J. Palmer, D. M. Pfund, J. L. Fulton, M. Newville, Y. J. Ma, and E. A. Stern, J. Phys. Chem. A 101, 9632 (1997)

${ }^{23}$ G. Ferlat, A. S. Miguel, J. F. Jal, J. C. Soetens, P. A. Bopp, I. Daniel, S. Guillot, J. L. Hazemann, and R. Argoud, Phys. Rev. B 63, 134202 (2001).

${ }^{24}$ A. Filipponi, S. De Panfilis, C. Oliva, M. A. Ricci, P. D'Angelo, and D. T. Bowron, Phys. Rev. Lett. 91, 165505 (2003).

${ }^{25}$ D. T. Bowron, J. Phys.: Conf. Ser. 190, 012022 (2009).

${ }^{26}$ G. Chillemi, G. Mancini, N. Sanna, V. Barone, S. D. Longa, M. Benfatto, N. V. Pavel, and P. D'Angelo, J. Am. Chem. Soc. 129, 5430 (2007).

${ }^{27}$ G. Mancini, N. Sanna, V. Barone, V. Migliorati, P. D'Angelo, and G. Chillemi, J. Phys. Chem. B 112, 4694 (2008).
${ }^{28}$ P. D’Angelo, A. Di Nola, M. Mangoni, and N. V. Pavel, J. Chem. Phys. 104, 1779 (1996).

${ }^{29}$ P. D'Angelo, V. Migliorati, G. Mancini, and G. Chillemi, J. Phys. Chem. A 112, 11833 (2008)

${ }^{30}$ C. Hardacre, Annu. Rev. Mater. Res. 35, 29 (2005).

${ }^{31}$ K. Nishikawa, S. Wang, H. Katayanagi, S. Hayashi, H. Hamaguchi, Y. Koga, and K. Tozaki, J. Phys. Chem. B 111, 4894 (2007).

${ }^{32}$ A. Filipponi and A. Di Cicco, Phys. Rev. B 52, 15135 (1995).

${ }^{33}$ A. Filipponi, A. Di Cicco, and C. R. Natoli, Phys. Rev. B 52, 15122 (1995).

${ }^{34}$ A. Elaiwi, P. B. Hitchcock, K. R. Seddon, N. Srinivasan, Y.-M. Tan, T. Welton, and J. A. Zora, J. Chem. Soc. Dalton Trans. 1, 3467 (1995).

${ }^{35}$ See supplementary material at http://dx.doi.org/10.1063/1.3625920 for Figs. $1 \mathrm{~S}$ to $4 \mathrm{~S}$.

${ }^{36}$ J. D. Holbrey, W. M. Reichert, M. Nieuwenhuyzen, S. Johnston, K. R. Seddon, and R. D. Rogers, Chem. Commun. 1, 1636 (2003).

${ }^{37}$ J. Kutuniva, R. Oilunkaniemi, R. S. Laitinen, J. Asikkala, J. Karkkainen, and M. K. Lajunen, Z. Naturforsch 62, 868 (2007).

${ }^{38}$ P. D'Angelo, V. Migliorati, and L. Guidoni, Inorg. Chem. 49, 4224 (2010).

${ }^{39}$ P. J. Merkling, R. Ayala, J. M. Martinez, R. R. Pappalardo, and E. S. Marcos, J. Chem. Phys. 119, 6647 (2003).

${ }^{40}$ J. L. Fulton and M. Balasubramania, J. Am. Chem. Soc. 132, 12597 (2010).

${ }^{41}$ T. Endo, T. Kato, and K. Nishikawa, J. Phys. Chem. B 114, 9201 (2010). 